\title{
ON THE TWO ORIGINS OF EXISTENTIAL SENTENCES
}

\author{
ISAO INOUE \\ Nagoya University
}

\begin{abstract}
In this paper, it is shown that there are structural differences between locational and periphrastic existential sentences (hereafter, abbreviated as ESs). It is argued that these structural differences can be accounted for by the hypothesis that locational and periphrastic ESs develop from two different deictic there-constructions. The reanalysis processes by means of which these two ES subcategories develop are argued to be governed by the principle of economy. This principle is proposed as a preliminary answer to the question: how do children expand their repertoire of constructions?*
\end{abstract}

\section{Introduction}

In locational existential sentences ${ }^{1}$ like (1) (hereafter, abbreviated as locational ESs) we can prepose locational phrases to the sentence initial position by means of $w h$-movement:

(1) a. There is a dog in the garden.

b. Where is there a dog?

(2) They thought you would know where there was a youth hostel.

$(\text { LL-04.2 1795) })^{2}$

However, we cannot apply wh-movement to periphrastic ESs like (3a) in a parallel manner, as pointed out by Williams (1984: 133-134):

(3) a. There was someone happy.

b. *How happy was there someone?

This property is peculiar to periphrastic ESs, because wh-movement of predicates is in general allowed:

(4) How happy do you consider Bill?

* I am grateful to D. M. Rines, B. Perry, M. Morrone, and T. Omuro for their valuable comments on earlier drafts of this study.

1 For the structural definitions of ES subcategories, see Milsark (1974: Part II).

$2 \mathrm{LL}$ is an abbreviation of the London-Lund Corpus of Spoken English.

English Linguistics 10 (1993) 50-74 - 50 -

(C) 1993 by the English Linguistic Society of Japan 
There are other syntactic differences between these two ES subcategories, as observed by Williams (1984) and Takahashi (1990). We can delete post-copular NPs in locational ESs, but not in periphrastic ESs:

( 5 ) When it goes into the house, it'll go into one of the bedrooms. But there's also $\phi$ in the drawing-room at home. (it $=$ a big chest of drawers)

(LL-04.1 1639)

(6) a. ${ }^{*}$ There was someone sick but there wasn't $\phi$ dead.

(Williams (1984: 138))

b. ${ }^{*}$ There was someone playing the piano, but there wasn't $\phi$ singing.

(Takahashi (1990))

c. ${ }^{*}$ There was someone tortured, but there wasn't $\phi$ killed.

(Takahashi (1990))

While locational phrases can be preposed to the sentence initial position, such an option is not available in periphrastic ESs:

(7) Outside this junk shop there were five buckets actually.

(LL-04.2 834)

( 8 ) a. There was a man sleeping/killed/sick.

b. *Sleeping/killed/sick there was a man.

(Takahashi (1990))

Given these syntactic differences between locational and periphrastic ESs, it seems quite natural to hypothesize that there are some structural differences between these two ES subcategories.

In this paper I would like to show that the difference between locational and periphrastic ESs can be accounted for by the hypothesis that these two ES subcategories develop from two genetically different origins. In section 2, I will examine structural differences between locational and periphrastic ESs. Section 3 will show developmental routes that can be followed by there-constructions. In section 4, I will consider how ES subcategories develop. In section 5, the structure of periphrastic ESs will be identified. ${ }^{3}$

2. The Structural Differences between Locational and Periphrastic ESs

It has been suggested in section 1 that there are some structural

3 In this paper, I will adopt the research strategy developed by Kajita (1977, 1986). 
differences between locational and periphrastic ESs. First, we try to identify the structure of locational ESs. Consider discourse (9):

(9) A: You mean there's a mark on the film.

B: There's a mark on the film. There's a red mark when you get to the end.

A: [m] (the sound of " $m$ ")

(LL-1-7 1494-1498)

In this discourse, speaker $\mathrm{B}$ specifies the location of the entity a mark by means of two different ways, namely by the locational phrase on the film and by the temporal expression when you get to the end. The fact that these two expressions perform the same function in the discourse (9) suggests that these two ES subcategories share some syntactic properties.

Our prediction is borne out by the following temporal ESs. First, observe that temporal phrases can be moved to the sentence initial position in exactly the same way as in the locational ES (7).

(10) a. Later in the evening there was a great firework display. (LL-12 6962)

b. In my time at Eton there was a French master.

(LOB R09 103) ${ }^{4}$

Second, we can apply wh-movement to form relative clauses in both locational and temporal ESs:

(11) a. And I went to some second year seminars where there are only about half a dozen people.

(LL-1-5 40)

b. The rally comes at a time when in spite of carefully worded statements by the Prime Minister there is an air of electoral expectancy.

(LOB A-BL 573)

Third, as in locational ESs like (5), we can delete post-copular NPs in temporal ESs:

(12) A: There's an excruciating shortage of seats in the library.

B: Well, there isn't $\phi$ at the moment.

(LL-3-3 136)

Fourth, we can delete locational and temporal phrases in ESs, generating ontological ESs like (13a, b):

(13) a. Is there any milk?

b. There won't be a meeting.

(LL-08 3534)

These syntactic phenomena common to locational and temporal ESs lish.

${ }^{4} \mathrm{LOB}$ is an abbreviation of the Lancaster-Oslo/Bergen Corpus of Written Eng- 
can be accounted for if we assume that these two ES subcategories have the same structure (14), parallel to (15):

(14) there $\left[\mathrm{v}^{\prime \prime}\left[\mathrm{v}^{\prime}\right.\right.$ be NP] (Location/Time)] (ES)

(15) John $\left[\mathrm{v}^{\prime \prime}\left[\mathrm{v}^{\prime}\right.\right.$ ate meat] (at a restaurant/at noon)]

If the parallelism between (14) and (15) is correct, we expect that locational and temporal ESs parallel to (16b) and (17b) below should exist. In (16b), the locational phrase in the kitchen and in (17b), the temporal phrase till 4.30 are separated from the rest of the sentence by a comma.

(16) a. I typed the letter in the kitchen.

b. In the kitchen, I typed the letter.

(17) a. I waited patiently enough for an interview till 4.30.

b. Till 4.30, I waited patiently enough for an interview.

Our expectation is borne out by locational ESs in (18) and temporal ESs in (19):

(18) a. In verses 9-16, there is a special appeal to the remnant of the people then in the land. (LOB D-BL.2 1651)

b. In a number of European countries, there are very well developed schools of business.

c. It seems to me that in law, there's a problem.

(LL-06.1 718)

(LL-3-3 164)

(19) a. After a trickle of the sixteenth century, there is a great mass of material of the seventeenth and eighteenth, some of it very fine.

(LOB J-BL.2 3350)

b. And then round about that time, there was the Lakeside Hotel dance.

(LL-12 3173)

c. During the early evening, there were great tug of war matches.

(LL-12 6949)

Quirk et al. (1985: §§ 8.15 and 8.36) observe that such a sentence initial position is closely associated with sentence adverbials with scenesetting function for what follows and that such an option is not easily available for predication adjuncts. The fronting of predication adjuncts produces awkward or unacceptable sentences like (20b) and $(21 \mathrm{a}, \mathrm{b})$ in contrast to $(22 \mathrm{~b})$ and $(23 \mathrm{a}, \mathrm{b})$ :

(20) a. She $\left[\mathrm{v}^{\prime \prime}\left[\mathrm{v}^{\prime}\right.\right.$ kissed her mother on the cheek $\left.]\right]$

b. ?On the cheek, she kissed her mother.

(21) a. ${ }^{*}$ On the cheek, it is a fact that she kissed her mother.

b. ${ }^{*}$ On the cheek, the fact is that she kissed her mother.

(22) a. She $\left[\mathrm{v}^{\prime \prime}\left[\mathrm{v}^{\prime}\right.\right.$ kissed her mother] on the platform] 
(23) a. On the platform, it is a fact that she kissed her mother.

b. On the platform, the fact is that she kissed her mother.

However, locational and temporal phrases in ESs can be separated by a comma, as we have seen in (18)-(19), so that they cannot be considered to be $\mathrm{V}^{\prime}$ constituents like on the cheek in (20a). ${ }^{5}$ Therefore, ESs in (18) and (19) strongly argue for the structure (14) but not for the small clause (hereafter, abbreviated as SC) analysis (24), which is advocated by Stowell (1978, 1981), Chomsky (1981), Safir (1985) and Lumsden (1988).

(24) there $\left[\mathrm{v}^{\prime \prime}\left[\mathrm{v}^{\prime}\right.\right.$ be [sc NP Location] $\left.]\right]$

Locational phrases in ES function simply as adverbial modifiers, as represented in (14), because they are such peripheral constituents as to be separated by a comma in the sentence initial position.

Temporal ESs with non-eventive nouns like (25) provide another argument for (14).

(25) a. Just in case there's no toys on Christmas morning.

(LL-0.1 3867)

b. A colleague has kindly offered to baby-sit the only baby that there will be that evening.

(LL-07 3265)

As shown by $(26 \mathrm{a}, \mathrm{b})$ below, no subject-predicate relation can be found between non-eventive nouns and temporal phrases in (25).

(26) a. * No toys were on Christmas morning.

b. ${ }^{*}$ The baby was that evening.

So, we cannot assign SC analysis (27) to such temporal ESs.

(27) there $\left[\mathrm{v}^{\prime \prime}\left[\mathrm{v}^{\prime}\right.\right.$ be $[\mathrm{sc}$ NP Time $\left.\left.]\right]\right]$

To be more precise about the temporal ES, note that temporal ESs

5 A referee for this journal has argued against this analysis by pointing out sentence (ib):

(i ) a. John $\left[\mathrm{v}^{\prime \prime}\left[\mathrm{v}^{\prime}\right.\right.$ put his books on the table $\left.]\right]$

b. On the table, John put his books.

(Hornstein and Weinberg (1981: 82)) However, such a judgment is quite dubious, because Hornstein and Weinberg (1981: 82) rule out such sentences as in (ii) with no convincing reasons:

(ii ) a. ?* On the table John put his hands.

b. ? On the table John put his cards.

In complete contrast to (20b) and (iia, b), ESs such as in (18)-(19) and sentences like $(22 \mathrm{~b})$ and $(23 \mathrm{a}, \mathrm{b})$ show no such idiosyncratic variations. As Quirk et al. (1985: $\S 8.36)$ note, the fact that there is such a structural difference as shown in (20a) and (22a) can be highlighted by the difference in acceptability between (21a, b) and $(23 \mathrm{a}, \mathrm{b})$. 
with eventive nouns like (28a, b) may be compatible with the SC analysis (27), because a subject-predicate relation exists between eventive NPs and temporal phrases, as we see in (29).

(28) a. There was a big law case last year.

b. There will be an announcement within a couple of weeks.

(LL-3-2 835)

(29) a. The big law case was last year.

b. The announcement will be within a couple of weeks.

However, this does not mean that the correct structural representation for such ESs must be (27). It is fair to say that such temporal ESs are ambiguous between the two structural analyses, namely (14) and (27). But note that only (14) is compatible with all temporal ESs, whether they involve eventive or non-eventive nouns. Therefore, the correct generalization seems to be that temporal ESs have the structure (14).

Now turn to periphrastic ESs such as in (30):

(30) a. There was a man drunk at the pub this afternoon.

b. There must be about forty keys hanging.

c. There were two things criticized.

Stowell $(1978,1981)$ argues that ESs involving AP, Ving, and Ved such as in (30) have complement structures identical with those embedded under such verbs as want and like:

(31) a. She wanted [her martini very dry]

(Virginia Rich, The Cooking School Murders, p. 102)

b. He likes [his coffee strong]

(Chuang Chi-chang, English Verbs at Work, p. 481)

(32) a. The Americans don't want [Cruba financing a private army]

(David Williams, Copper, Gold and Treasure, p. 12)

b. He didn't like [her wearing jeans]

(LOB N16 28)

(33) a. Mayor Dalkey wanted [a lot of them transferred to Midway, with their 747 jets]

(Studs Terkel, Working, p. 562)

b. I'd like [that room made into a real artist's studio]

(Virginia Rich, The Cooking School Murders, p. 202)

It is clear that the bracketed strings in (31)-(33) form clausal complements, because verbs like want and like can take alternative complements involving to be:

(34) a. The FBI wants [Frank alive]

b. The FBI wants [Frank to be alive] 
(35) a. I want [you standing up when the judge arrives]

b. I want [you to be standing up when the judge arrives]

(36) a. I want [it done at once]

b. I want [it to be done at once] (Zandvoort (1962: 51)) The correspondence between the (a) and (b) versions in (34)-(36) leads us to suppose that verbs like want and like take clausal complements. Therefore there arises the possibility that periphrastic ESs also involve clausal complements.

There are more direct empirical reasons for assuming clausal complement structures in periphrastic ESs. Hannay (1985: Ch. 3) observes that what is asserted to exist in (37) is not a ship, but rather the whole state of affairs designated by the post-copular clausal structure a ship sunk outside the exclusion zone:

(37) A: What on earth has happened?

B: There's just been a ship sunk outside the exclusion zone.

Hannay (1985: Ch. 1) also argues that in (38) the existence of two soldiers is asserted, whereas in periphrastic ES (39), an event propositionaly equivalent to (40) is asserted to exist.

(38) There were two soldiers who were shot dead in Belfast last night.

(39) There were two soldiers shot dead in Belfast last night.

(40) Two soldiers were shot dead in Belfast last night.

Further evidence to support the assumption that be verb in periphrastic ESs can take clausal complements is provided by contact clause ESs like (41):

(41) a. There were three black boys were walking along the street.

b. There's a lot of people are quite well off too.

(LL-2-7 929)

(LL-04.2 4165)

Hannay (1985: Ch. 4) argues that what is appropriate in answer to question (42) is contact clause ES (43), but not relative clause ES (44):

(42) What happened?

(43) There was something hard fell on the floor.

(44) There was something hard that fell on the floor.

Lambrecht (1988) also observes that a speaker who utters (45) wishes to express a simple proposition such as (46):

(45) There was a ball of fire shot up through the seats in front of 
me.

(46) A ball of fire shot up through the seats in front of me.

Thus, there is convincing evidence that provides support for the view that the periphrastic ES involves a clausal complement structure. So, let us tentatively suppose that periphrastic ESs have structure (47):

(47) there be [NP Predicate] (Periphrastic ES)

It seems quite natural to assume that the ES family can be divided into two subgroups. One consists of locational, temporal, and ontological ESs and the other consists of periphrastic and contact clause ESs. Let us call the former subgroup entity ES, and the latter proposition ES. The entity ES asserts the existence of an entity denoted by the post-copular NP, while the proposition ES involves an assertion of the existence of a state-of-affairs which is designated by a clausal complement embedded under be.

\section{The Developmental Sequence of There-Constructions}

In section 2, we have seen that there are substantial similarities in syntactic behavior between the locational and the temporal ES, and suggested that these two ES subcategories have essentially the same structure, involving an NP complement. We have also presented a number of observations which argue for the clausal complement structure analysis of the periphrastic and the contact clause ES. This structural difference leads us to propose that the ES family can be divided into two subgroups, namely the entity ES, comprising locational, temporal, and ontological ESs, and the proposition ES, which consists of periphrastic and contact clause ESs. In this section, we will examine why these two subgroups have developed in the ES family by investigating how children acquire various types of there-constructions relevant to our discussion.

In order to study how children acquire there-constructions, I examined the corpus of speech of the child named Peter studied by Bloom (1970), using the Child Language Data Exchange System (CHILDES) database (MacWhinney and Snow (1990)). The Corpus PETER contains 20 files, recorded between the ages of 1;9.7 and 3;1.21. ${ }^{6}$ Although I have mainly searched PETER, I have also ex-

6 In this paper, ages are given in the form of years;months.days as in 1;9.7 for 1 year, 9 months, and 7 days. 
amined the corpora of other two children, namely Adam and Shem in CHILDES database as well as published observations by Bloom (1973), Bloom et al. (1975), Braine (1976), Brown and Fraser (1964), Fletcher (1985), Hyams (1986), and Nelson (1973).

The developmental sequence of there-constructions can be divided into at least four stages. These four stages are summarized in (48)(51), with examples found in CHILDES which correspond to each developmental stage:

(48) 1st Stage

One word utterance with there alone.

Allison Age(1;4.3) (Allison pointing to Mother) There.

(Allison reaching for microphone; hold it) There.

(BLOOM73¥ALLISON1.CHA: 46, 51)

(49) 2nd Stage

There NP

a. Eric Age $(1 ; 10.0)$ (Eric picking up bird)

There ə birdie.

b. Eric Age(1;11.14) (Lois opens closet door; vacuum cleaner is inside) There cleaner.

(BLOOM70¥ERIC $¥$ BOOKERIC.CHA: 223, 245)

(50) 3rd Stage

There's NP

a. Allison Age(1;10.0) (Allison puts hand to head; looking at monitor) There's Allison.

(BLOOM73 $¥$ ALLISON04.CHA: 12)

b. Gia Age(2;1.2) (Gia pointing to book on record-player cabinet) There's ə book.

(BLOOM70 $¥$ GIA $¥$ GIABOOK.CHA: 296)

(51) 4th Stage

There's NP VP

a. Peter Age $(2 ; 1.0)$ (Peter pointing to the box of tape he's holding) There's a tape go (a)round right there.

(BLOOM70¥PETER $¥$ PETER07.CHA: 139)

b. Peter Age(2;9.14) (Peter crashing horse with cow and girl, knocking horse down, knocking cow down) There's somebody's gonna crash on him, sssəo! This horsie fall down too. And this cow fall down, and this.

(BLOOM70¥PETER $¥$ PETER18.CHA: 3670)

c. Peter Age $(2 ; 10.21)$ This is the mommy cow. (Peter 
squeezing) There's milk coming out of it.

(BLOOM70¥PETER $¥$ PETER19.CHA: 358)

d. Adam Age(3;6.0) I gon' put some in de jeep.

Dere's a man driving and (we'll) need somebody... And dis somebody sitting in de back.

(BROWN¥ADAM¥ADAM32.CHA: 74)

There's NP Location

e. Eric Age(2;0.7) (Eric pointing to pigeon walking on street) There's $ə$ birdie in there.

(BLOOM70 $¥$ ERIC $¥$ BOOKERIC.CHA: 385 )

f. Peter Age(2;1.0) (Peter takes box of tape over to Jenny, who is lying on floor, showing tape to her) There's a tape in there.

(BLOOM70¥PETER $¥$ PETER07.CHA: 149)

g. Allison Age $(2 ; 10.0)$ (Allison pointing to can) There's some in there. (BLOOM73¥ALLISON06.CHA: 126)

There-constructions in stages 1 and 2 do not yet make up a sentential structure. Bloom (1973) and Braine (1976: Ch. 2) note that in these stages there is used to point out objects or people that children notice or find. As context descriptions in (48) and (49) indicate, there is usually accompanied by some kind of pointing or head turning gesture. By uttering there, children are directing the hearer's attention to the location specified by there. Therefore, we can safely assume that there in stages 1 and 2 is a deictic adverb.

At the third stage, children can first use there-constructions of a fullfledged sentence form. The problem here is whether sentence initial there is a deictic adverb or an expletive subject NP. Lakoff (1987: 474, 490) argues that the property which distinguishes between the deictic adverb there and the expletive there is an illocutionary force constraint imposed on the deictic adverb there:

(52) The deictic adverb there directs the hearer's attention to the location of the entity and brings it to the hearer's attention that the entity is at the specified location.

The constraint (52) implies that a pointing gesture may accompany deictic there-constructions, but not ESs. It is clear that children's behaviors specified in (50) satisfy this condition. Therefore, we assume that there sentences in (50) are deictic there-constructions, comparable to deictic adverb sentences in (53):

(53) a. Peter Age $(2 ; 3.21)$ (Peter pointing to the 4 chairs) 
Right there are chairs, there chairs.

(BLOOM70¥PETER $¥$ PETER11.CHA: 227)

b. Peter Age(2;9.14) (Peter seeing bolt)

Right here's one.

(BLOOM70¥PETER $¥$ PETER18.CHA: 1800)

Next, let us turn to stage 4 , where two additional there-constructions come to be included in the children's repertoire:

(54) a. There's NP VP.

b. There's NP Location.

The contextual situation in which $(54 \mathrm{a}, \mathrm{b})$ are employed by children is essentially the same as in stage 3 . This suggests that there is a very strong possibility that there in $(54 \mathrm{a}, \mathrm{b})$ can be analyzed as a deictic adverb.

First, consider (54a), illustrated by examples (51a, b, c, d). As contextual descriptions of $(51 \mathrm{a}, \mathrm{b}, \mathrm{c}, \mathrm{d})$ indicate, all the there-constructions in these examples are accompanied with pointing gestures or demonstrative performances giving them a somewhat dramatic quality. These utterances assert the occurrence of events and thereby direct the hearer's attention to the events designated by the clausal complements. Thus, the examples in (51a, b, c, d) can be considered to be deictic there-constructions involving clausal complements.

Evidence to corroborate this analysis can be provided by examples containing here in children's speech used in similar contexts as in (51a, b, c, d):

(55) a. Peter Age(3;1.21) Put the wheels and headlights.

Here's a wheel coming.

(BLOOM70¥PETER ¥PETER20.CHA: 2864)

b. Shem Age(2;9.27)

Shem: But here's water coming out o dere.

Investigator: Yea. I don't know why he's letting that water come out.

(CLARK $¥$ SHEM27A.CHA: 444)

c. Adam Age $(4 ; 1.0)$ Here I go New York. OK. Here's de train go. (BROWN $¥$ ADAM $¥$ ADAM43.CHA: 1415)

Here we can more safely assume that here in (55) is a deictic adverb, because English does not employ here as an expletive. It then follows that the here-constructions in (55) can be analyzed as deictic adverb constructions of the form (56), in parallel to (54a).

(56) Here's NP VP. (deictic)

Thus, the deictic here-constructions in (55) may be sufficient to guaran- 
tee the deictic adverb analysis of (54a).

Next, consider (54b). Note that contextual descriptions accompanying $(51 \mathrm{e}, \mathrm{f}, \mathrm{g})$ of the form (54b) are comparable to those accompanying the deictic there-constructions $(50 \mathrm{a}, \mathrm{b})$. If we apply the same criterion (52) to the there-constructions $(51 \mathrm{e}, \mathrm{f}, \mathrm{g}$ ) in deciding the status of the sentence initial there, $(51 \mathrm{e}, \mathrm{f}, \mathrm{g})$ could be considered to be deictic thereconstructions. ${ }^{7}$ Perhaps children add the locational expression to the deictic there-construction there be NP in order to specify more precisely the location designated by the sentence initial deictic adverb there, as in the following utterances of children:

(57) a. Peter Age $(2 ; 1.0)$ (Peter noticing truck has a spare tire) What's that there, under there?

(BLOOM70¥PETER $¥$ PETER07.CHA: 1039)

b. Peter Age(2;5.3) (Peter pointing bag) Right there, in there! (BLOOM70¥PETER $¥$ PETER13.CHA: 730)

c. Peter Age $(2 ; 10.21)$ Yeah, right there, right in my bed room. (BLOOM70¥PETER $¥$ PETER19.CHA: 158)

d. Shem Age(2;3.2) In there, in the room.

(CLARK¥SHEM63.CHA: 601)

e. Eve Age $(2 ; 0.0)$ An orange house right there, by green one.

(BROWN $¥ E V E ¥ E V E 14 . C H A: 1028$ )

If these observations are correct, (54b) can also be regarded as a deictic there-construction (see Inoue (1991) for further discussion).

To summarize, we have seen that all of the there-constructions used by children in stages 1-4 satisfy the illocutionary force condition (52), and therefore we have proposed that they can be analyzed as deictic constructions. Thus we can call these four stages deictic stages. In the next section, I will consider what triggers the evolution from the homogeneous deictic stage to the heterogenous stage where both deictic and expletive there-constructions occur.

7 A referee suggests that the pointing gesture accompanying there-constructions like $(51 \mathrm{e}, \mathrm{f}, \mathrm{g})$ might be triggered by the deictic adverb there in the end position, so that sentence initial there can be analyzed as an expletive subject. But Hyams (1986: 90) argues on independent grounds that Eric began to use expletive subjects at the age of $2 ; 2.3$, two months after (51e) was uttered. The time lag of two months is significant when we take into consideration the rapid rate of children's language development at the age of two. Thus, we can safely maintain our deictic adverb analysis of $(51 \mathrm{e}, \mathrm{f}, \mathrm{g})$. 


\section{On the Emergence of ESs}

First, recall that the earliest and most basic deictic there-constructions are of the form (58):

\section{(58) There's NP. (deictic)}

The deictic there-construction (58) is used when the speaker draws the hearer's attention to the presence of a person or thing designated by the post-copular NP. By uttering deictic there, the speaker picks out a location in the perceptual field where the entity in question exists. The deictic locative adverb there in children's speech typically refers to concrete locations of concrete objects in their perceptual space, as illustrated in (59):

(59)

Peter Age $(2 ; 3.0)$

Adult: Where's the car?

Peter: Huh? There's the car.

(BLOOM70¥PETER $¥$ PETER10.CHA: 2778)

Thus, which location the deictic adverb there designates can be easily defined in concrete and specific terms, so that children can understand and use deictic there-constructions of the form (58) without difficulty. Therefore, it seems quite natural to regard (58) as a prototype deictic there-sentence, which is the earliest and most basic subcategory of deictic there-sentences.

However, such a function originally assigned to the deictic there in the prototype (58) is not necessarily compatible with the deictic there in (54a).

(54a) There's NP VP. (deictic)

By uttering a sentence of the form (54a), children direct the hearer's attention to an event or a state denoted by a sentential complement, not to a physically present concrete object. The location designated by there in (54a) can not be defined easily in concrete terms. There in (54a) refers to the vague abstract location of an abstract entity such as an event or a state. Thus, in children's speech, the deictic construction (54a) can be considered to be a very atypical construction temporarily employed by children to satisfy a communicative demand. This developmental sequence is not an isolated case, because there are many examples of similar developmental patterns where new communicative intentions are expressed by temporary unstable non-standard linguistic forms, which are later replaced by more stable unmarked expressions. For example, Slobin (1973: 185-186) observes that shortly before the 
emergence of the perfect tense, children attach now to statements about the past, producing sentences like the following which perform the same function as the perfect tense.

(60) Now I closed it.

Sentences like (60) are unstable, because now, which typically refers to the present moment, cooccurs with the past tense closed. Such unstable sentences like (60) are soon replaced by present perfect sentences like (61):

(61) I've closed it.

Thus, it is natural to suppose that some mechanisms will be triggered to ease the burden imposed by the atypical deictic construction (54a).

We can think of two possibilities in the case of the following subcategory of (54a):

(62) there be [NP Ving X] (deictic)

The first is to divide (62) into two parts, restoring the basic pattern (58) in the first half and expressing the original propositional content in the second half:

(63) there be NP, Ving X. (deictic)

(64) a. There is Derek, running around the track.

(Lakoff (1987: 502))

b. A: ... and then if something happened we'd deal with it.

B: So something happened.

A: Yeah. And here I am, dealing with it.

(Michael Weller, Loose Ends, p. 359)

c. . . but when I walked into the house, there he was, sitting in the red wing chair at the table in the living room, ... (New Yorker, June 23, 1986, p. 25)

In (63), as exemplified in (64), the principal statement that the speaker intends to make is expressed by the latter half of the statement with the first half playing only the secondary role of catching the hearer's attention. Thus in $(64 a, b, c)$ the main propositions correspond to those expressed by the following sentences:

(65) a. Derek is running around the truck.

b. I am dealing with it.

c. He was sitting in the red wing chair at the table in the living room.

In this way (63) can both retain the essentially same communicative function as the unstable (62), and restore the prototype (58). 
The second solution is to reanalyze the deictic adverb there as an expletive NP, changing the deictic sentence to ES:

(66) there be [NP Ving X] (ES)

Because there in (66) can no longer indicate a location in physical space, there is little possibility of a conflict between the deictic locative adverb there and the post-copular propositional expression in (62).

Although there in deictic constructions typically refers to the concrete location of a concrete object, such a requirement is no longer imposed on periphrastic ESs as in (67).

(67) There was a crowd of people shouting obscenities outside 10 Downing Street.

What is at issue in (67) is not the location of a crowd of people but the existence of the event corresponding to (68):

(68) A crowd of people were shouting obscenities outside 10 Downing Street.

By reanalyzing the deictic adverb there as an expletive NP, children can produce periphrasitc ESs like the following after Stage 4, replacing atypical (62):

(69) a. Adam Age(4;7.0) There's always some coming in?

(BROWN $¥$ ADAM $¥$ ADAM50.CHA: 1315 )

b. Shem Age $(2 ; 10.25)$ Because there was ə van coming.

(CLARK $¥$ SHEM30A.CHA: 638)

It is quite apparent why periphrastic ESs like (67) and (69a, b) come to take clausal complements. It is because the periphrastic ES (66) is derived from the corresponding deictic there-construction (62), which originally takes a clausal complement.

However, a parallel explanation in terms of the reanalysis of the deictic adverb there is difficult to offer for periphrastic ESs involving Ved and Adj, such as in (70), because no corresponding deictic there sentences are found in the corpora, PETER, ADAM, and SHEM.

(70) a. There has been a whole box stolen.

b. There were several students ill.

So, let us assume that after (71) is realized as (66), children extend the variety of the predicate to produce periphrastic ESs like (70a, b).

(71) there be [NP Predicate] $(=(47)) \quad$ (Periphrastic ES) This assumption is in accord with the fact that periphrastic ESs involving Ving occur first in children's corpora among three subcategories of periphrastic ESs.

The reanalysis of the deictic adverb there as an expletive NP can also 
be applied to deictic there-constructions with finite complement clauses like (51a, b), producing contact clause ESs like (41a, b) and (72):

(72) There was a very good example of this was at the battle of Tennenberg.

(LL-2-3 1040)

As Lambrecht (1988) and Hannay (1985: §4.4) observe, what is asserted to exist in a contact clause ES like $(41 \mathrm{a}, \mathrm{b})$ and (72) is an event or a state denoted by the embedded finite clausal complement.

If these reanalysis hypotheses are correct, they give us another piece of evidence to support the view that periphrastic and contact clause ESs can be considered to share essentially the same clausal complement structure, if we disregard the finite/nonfninite distinction.

Now let us consider the case of (54b):

(54b) There's NP Location. (deictic)

We have been assuming that the deictic there-construction (54b) is produced by children by adding a locational expression to the prototype (58) in order to specify more precisely the location designated by deictic there, as we disscussed in section 3 .

(58) There's NP. (deictic)

However, this option selected by children is illegitimate in the following sense. Quirk et al. (1985: § 2.32) and Grimshaw (1990: 148-149) suggest that adjucts can cooccur only when they introduce different information, as in (73):

(73) a. Many people eat in restaurants in London.

b. Pete destroyed the city on Tuesday at two o'clock.

Note that this condition is violated in (54b). In principle, no different information is conveyed by the deictic adverb there and the locational expression added at the end position in (54b). Thus, (54b) is another unstable temporary construction bound to be replaced by a stable legitimate one. Here we can suggest two developmental possibilities to get rid of the abnormality residing in $(54 \mathrm{~b}) .^{8}$

The first solution is to make the added locational expression into the part of a proposition separate from the rest of the construction, as in the case of (63). By this process, we can regain the structure of the prototype deictic there-construction (58):

8 The following proposal concerning (54b) is a revised version of the proposal presented in Inoue (1991). In the discussion below, I will introduce the principle of economy to account for why (54b) takes a particular course of development, but not others. 
(74) There's NP, Location.

Deictic sentences of the form (74) are found after Stage 4. A pause (indicated by \# in (75)) inserted before the locational expression in the following examples clearly shows that the suggested operation has been carried out:

(75) a. Peter Age(2;2.13) (Peter sees another barrel, reaches for it) There's another one \# right there.

(BLOOM70¥PETER $¥$ PETER09.CHA: 540)

b. Shem Age(2;3.28)

Investigator: You're looking for what?

Shem: Looking for bugs. There’s de buggies \# right here. (CLARK $¥$ SHEM06.CHA: 1037)

Such tone unit separation by a pause as found in (75) is usually marked off by a comma:

(76) a. Ah! There's the tree, in the garden.

b. There's your brother, over by the bar.

c. There she is, by the phone box.

The second approach to the problem of double specification of location is to reanalyze the sentence initial deictic adverb there as an expletive subject NP on the model of deictic pronoun sentences such as in (77): $:^{9}$

a. Peter Age $(2 ; 1,0)$ (Peter pointing to horse)

That's a doggie right there.

(BLOOM70¥PETER $¥$ PETER07.CHA: 4100)

b. Peter Age $(2 ; 4.15)$ (Peter offering Lois his banana) That's mine here.

(BLOOM70¥PETER $¥$ PETER12.CHA: 1027)

c. Peter Age(2;4.15) (Peter gesturing to animals) That's a animal right there.

(BLOOM70¥PETER $¥$ PETER12.CHA: 3650)

Deictic pronoun sentences like $(77 \mathrm{a}, \mathrm{b}, \mathrm{c})$ are normally used in the same way as deictic there-constructions like (54b) and (58) (cf. Lakoff (1987: 481)). This observation can be confirmed by the following discourse, where these two types of constructions are used in the same situational context:

${ }_{9}$ Here we assume that the locative expressions in $(77 a, b, c)$ can be analyzed as $\mathrm{V}^{\prime \prime}$ constituents. 
(78) Peter Age(2;3.24) (Peter pointing to Patsy) And there's Patsy. (Peter pointing to Lois) That's Lois.

(BLOOM70¥PETER $¥$ PETER11.CHA: 1663-1666)

We can assume that the striking similarity between these two types of constructions both in linear order sequence and in pragmatic usage, as found in (77) and (78), motivates the process which weakens the locative meaning of the deictic adverb there and renalyzes it as an expletive subject.

If this reanalysis process is applied to (54b), the resulting structure would be either $(79)$ or $(80)$ :

(79) there $\left[\mathrm{v}^{\prime \prime}\left[\mathrm{v}^{\prime}\right.\right.$ be NP] Location]

(80) there $\left[\mathrm{v}^{\prime \prime}\left[\mathrm{v}^{\prime}\right.\right.$ be [NP Location]]]

Recall that the locational expression in (54b) is originally appended to (58) as an additional piece of information to clarify the specific location of the entity designated by the post-copular NP, so that the locational expression can be considered to be a $\mathrm{V}^{\prime \prime}$ constituent, as in (79). Therefore, deictic constructions (54b) and (58) are both basically locative constructions of the same category. Thus, the post-copular NP and the locative expression in (54b) cannot be considered to constitute a sentential complement. If these assumptions are correct, the most economical way of restructuring (54b) is to reanalyze (54b) as (79). Economical here means preserving the structural properties of the prototype construction as much as possible. In other words, the development of a new construction will be executed as much as possible through old available grammatical patterns which have been firmly established in the children's grammar. Let us call this constraint the principle of economy. ${ }^{10}$

As we argued in section 2, the parallelism between locational and temporal ESs gives strong evidence for (79). Furthermore, the struc-

10 This naming accidentally happens to be the same as that proposed in Chomsky (1992). It goes without saying that this principle has nothing to do with Chomsky's, because the former is proposed in order to restrict the possible course of child language development from $G(\text { rammar })_{i}$ to $G(\text { rammar })_{i+1}$. This principle is related to the principle (i), proposed by Slobin (1973: 184-185), who accounts for various cases of child language development.

(i ) New functions are first expressed by old forms.

Thus, it seems that there are promising sources of independent motivation for the principle of economy. 
ture (79) is also supported by the fact that the clausal structure of the type (81) is rare:

(81) [NP Location]

(82) a. *I consider John off my ship.

b. I consider John to be off my ship.

(83) a. $\left(^{*}\right)$ We thought him out of the country.

b. We thought him to be out of the country.

(84) a. $(*)$ They believe the cat in the garden.

b. They believe the cat to be in the garden.

(85) a. ??She liked her car in the same spot.

b. She liked her car to be in the same spot.

(86) a. ??I expect that sailor off my ship.

b. I expect that sailor to be off my ship.

(87) a. (?)She wanted her car in the same spot.

b. She wanted her car to be in the same spot.

$\left({ }^{*}\right)$ in $(83)-(84)$, and (?) in (87a) indicate that there are considerable idiosyncratic variations in the acceptability judgment of these sentences, in remarkable contrast with universally acceptable ESs involving locational phrases. For example, while my informant rejects (83a) and (84a) as completely odd, Rothstein (1983: 68) accepts them. These facts lead us to suppose that the clausal structure with the locative predicate can be considered to be a marked rare type. Thus, we conclude that (54b) is reanalyzed as (79), and why (79) involves an NP complement can be accounted for by the principle of economy.

This proposal does not necessarily deny the possibility that locational ESs can derivatively acquire a clausal complement later. As Takahashi (1990) points out, locational ES examples like (88) show that the post-copular string NP Location can behave as a syntactic constituent:

(88) But there is heart in telling, and an intensive realism in the situation.

(LOB C-BL 455)

Parallel behavior can also be found in periphrastic ESs like (89):

(89) There were two uniformed officers standing under the porch, and two men in plain clothes with another in uniform talking to Pink in the drive.

(David Williams, Copper, Gold and Treasure, p. 133) Since coordinated sentences like (88) can be considered to be acquired later than non-coordinated simple locational ESs, let us suppose that locational ESs with the structure (80) are derivatively generated on the model of periphrastic ESs involving predicative PPs: 
(90) a. There was an eight to one majority in favour of the official policy.

(LL-05.1 6009)

b. There were 14 Chinese publications on sale.

(LOB B-BL B20 123)

c. There was no one else in sight.

(LOB H-BL F11 135)

d. There were more than twenty coke-fired blast furnaces in operation.

(LOB J-BL.2 1340)

Here we are assuming that the primary structure of locational ESs is (79) and the structure (80) is later acquired as a secondary option to satisfy communicative needs exemplified by ESs like (88).

To recapitulate, we have considered how ESs are generated and why periphrastic and locational ESs come to acquire different syntactic structures by examining the developmental sequence of there-constructions. It has been proposed that periphrastic and locational ESs develop from two different source constructions. The periphrastic ES is derived from the deictic there-construction involving an embedded clausal structure, while the loctional ES from the deictic there-construction with a non-clausal NP structure. It is also suggested that the locational ES derivatively obtains a clausal complement structure later so that in the later developmental stage, the locational ES can be considered to be ambiguous between an NP and a clausal complement structure. Consequently, the structural difference between the periphrastic and the locational ES is that only the locational ES can have a simple $\mathrm{NP}$ complement structure. We have proposed the principle of economy to account for why there-constructions take particular developmental courses as we have described above.

\section{Periphrastic ESs}

It has been tentatively proposed in section 4 that the deictic thereconstruction (54a) is syntactically reinterpreted as ES (91) via the reanalysis of deictic there as an expletive NP.

(54a) there be [NP VP] (deictic)

(91) there be [NP VP/Predicate] (ES)

But this reanalysis process is different from the other three restructuring processes proposed in section 4 :

(92) a. there be [NP Ving X] (deictic) $\longrightarrow$ there be NP, Ving $X$ (deictic)

b. there be NP Location (deictic) $\longrightarrow$ 


\section{there be NP, Location (deictic) \\ c. there be NP Location (deictic) $\longrightarrow$ there [[be NP] (Location)] (ES)}

The three restructuring processes $(92 \mathrm{a}, \mathrm{b}, \mathrm{c})$ can be characterized as processes restoring or preserving the prototype deictic construction (58), following the principle of economy proposed in section 4 .

(58) There's NP. (deictic)

On the other hand, the reanalysis process from (54a) to (91) apparently does not follow such a principle, because (91) is unique in taking an embedded clausal complement, in contrast to the prototype (58). If children follow the principle of economy in restructuring their grammar, children have to search for another model construction for the reanalysis of (54a).

It should be noted that among various subcategories of ES, locational ES (93) occurs first in children's corpora, including PETER, SHEM, and ADAM. So, it is reasonable to regard (93) as the prototype ES.

(93) there $\left[\mathrm{v}^{\prime \prime}\left[\mathrm{v}^{\prime}\right.\right.$ be NP] (Location)] (ES)

The prototype ES (93) inherits the non-clausal NP structure from the deictic prototype (58). When the reanalysis of (54a) is triggered, grammatical rules generating (93) have already been established in children's grammar. Therefore, the prototype ES (93) can function as a model for such a reanalysis process. The reanalysis process in question must satisfy two requirements. The first requirement is to assert the existence of a state or an event, which is the primary function of (54a). The second is to adopt the NP complement structure, which is the main formal property of the prototype ES (93). In order to meet these two requirements, the post-copular NP has to perform a dual function simultaneously:

(94) a. There [be NP]

b. There be [NP VP]

In (94a) the post-copular NP functions as a complement NP, while in (94b) the NP is a subject of the clausal complement.

Lambrecht (1988) proposes structure (95) in order to capture the intuition that one and the same NP performs the dual function in contact clause ESs: 
(95)

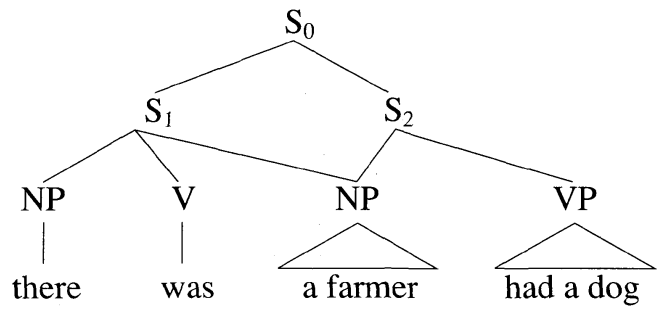

The structure (95) is closely related to the juxtaposition construction (96):

(96) There was a farmer; he had a dog.

We have been assuming that contact clause ESs like (95) can be derived from the deictic construction (54a) by means of the reanalysis of deictic there as an expletive NP. Supported by our reanalysis hypothesis and the principle of economy, we can account for why (95) is generated. The $S_{1}$ in (95) can be considered to adopt the NP complement structure of the prototype ES (93). On the other hand, the $\mathrm{S}_{2}$ in (95) preserves the semantic function of the deictic construction (54a).

Since we have been assuming that the periphrastic ES as well as the contact clause ES can be derived from (54a) via the same reanalysis process, it seems quite natural to suppose that periphrastic ESs in (97) $(=(30))$ also have the structure (95).

(97) a. There was a man drunk at the pub this afternoon.

b. There must be about forty keys hanging.

c. There were two things criticized.

Thus, the structural difference between entity ESs (i.e. locational, temporal, and ontological ESs) and proposition ESs (i.e. periphrastic and contact clause ESs) can be represented as follows:

(98) Entity ES there $\left[\mathrm{v}^{\prime \prime}\left[\mathrm{v}^{\prime}\right.\right.$ be NP] (Location/Time) $]$

(99) Proposition ES ${ }^{11}$

11 It might be argued that permitting such structures as (99) expands the set of possible grammars to such an extent that it becomes difficult to account for language learnability. However, permitting the structure (99) does not lead to such a problem, because we are trying to account for language learnability by restricting the possible extension of child's linguistic knowledge from G(rammar)i to $\mathrm{G}(\text { rammar })_{i+1}$. See Kajita (1986) for further discussion. 


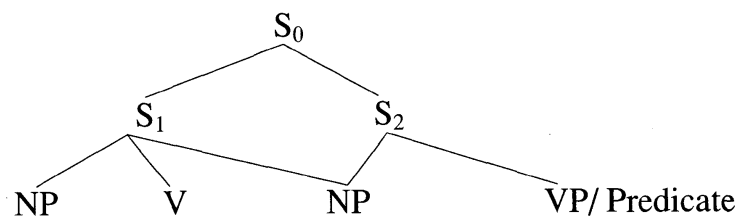

Because the proposition ES contains a rather complicated internal structure, it seems natural to regard the proposition ES as a marked ES subcategory. It follows that proposition ESs are acquired later than entity ESs, because proposition ESs are difficult for children to acquire. This prediction is verified by the fact that proposition ESs occur later than entity ESs in children's corpora in CHILDES database. The marked nature of proposition ESs is also reflected in the frequency of use. Of the total of 3899 ESs found in the London-Lund (LL) Corpus of Spoken English and in the Lancaster-Oslo/Bergen (LOB) Corpus of Written English, less than $10 \%$ are proposition ESs. It is also predicted that the application of grammatical rules to marked proposition ESs is not so easy as in the case of entity ESs. This prediction is verified by the observations presented in section 1 :

(100) a. *How happy was there someone? $\quad(=(3 b))$

b. ${ }^{*}$ Sleeping/killed/sick there was a man. $(=(8 b))$

(101) a. ${ }^{*}$ There was someone sick but there wasn't $\phi$ dead. $(=(6 a))$

b. *There was someone playing the piano, but there wasn't $\phi$ singing. $\quad(=(6 b))$

c. ${ }^{*}$ There was someone tortured, but there wasn't $\phi$ killed. $\quad(=(6 c))$

We may assume that in juxtaposition-like structures like (99), neither the movement of the predicate in $S_{2}$ across $S_{1}$ nor the deletion of the post-copular NP linking $S_{1}$ with $S_{2}$ are permitted. Although this proposal seems intuitively natural, it will have to be examined whether there are other linguistic facts to support this proposal. Here, it is interesting to note that in the LL and the LOB Corpus, proposition ESs are used only in the form of the simple declarative sentence.

\section{Conclusion}

In this paper, we have attempted to account for the structural difference between the locational and the periphrastic ES in terms of two 
different origins from which these two ES subcategories develop. We have argued that the reanalysis processes by means of which these ES subcategories develop are governed by the principle of economy. This principle has been put forward as a preliminary answer to the question: how do children expand their repertoire of constructions? We have seen that given the principle of economy and the hypothesis that deictic there-constructions are reanalyzed as ESs, we can account for why locational ESs acquire the NP complement structure and why periphrastic ESs come to acquire the hybrid structure between the NP complement and the clausal complement structure.

\section{REFERENCES}

Bloom, Lois (1970) Language Development: Form and Function in Emerging Grammars, MIT Press, Cambridge, MA.

Bloom, Lois (1973) One Word at a Time, Mouton, The Hague.

Bloom, Lois, Patsy Lightbown, and Lois Hood (1975) Structure and Variation in Child Language, Monographs of the Society for Research in Child Development 40.

Borkin, Ann (1973) "To Be or Not to Be," CLS 9, 44-56.

Braine, Martin (1976) Children's First Word Combinations, Monographs of the Society for Research in Child Development 41.

Brown, Roger, and Colin Fraser (1964) The Acquisition of Syntax, Monographs of the Society for Research in Child Development 29, 43-78.

Chomsky, Noam (1981) Lectures on Government and Binding, Foris, Dordrecht.

Chomsky, Noam (1992) A Minimalist Program for Linguistic Theory, MIT Occasional Papers in Linguistics 1.

Fletcher, Paul (1985) A Child's Learning of English, Basil Blackwell, Oxford.

Grimshaw, Jane (1990) Argument Structure, MIT Press, Cambridge, MA.

Hannay, Michael (1985) English Existentials in Functional Grammar, Foris, Dordrecht.

Hornstein, Norbert and Amy Weinberg (1981) "Case Theory and Preposition Stranding," Linguistic Inquiry 12, 55-92.

Hyams, Nina (1986) Language Acquisition and the Theory of Parameters, Reidel, Dordrecht.

Inoue, Isao (1991) "On the Genesis of There-Constructions," English Linguistics 8, 34-51.

Kajita, Masaru (1977) "Towards a Dynamic Model of Syntax," Studies in English Linguistics 5, 44-76.

Kajita, Masaru (1986) "Chomsky kara no Mittu no Bunkiten (Three Routes 
Branching off from Chomsky's Approach)," Gengo 15.12, 96-104.

Lakoff, George (1987) Women, Fire, and Dangerous Things, University of Chicago Press, Chicago.

Lambrecht, Knud (1988) "There Was a Farmer Had a Dog: Syntactic Amalgams Revisited," BLS 14, 319-339.

Lumsden, Michael (1988) Existential Sentences, Croom Helm, London.

MacWhinney, Brian, and Catherine Snow (1990) "The Child Language Data Exchange System: An Update," Journal of Child Language 17, 457-472.

Milsark, Gary (1974) Existential Sentences in English, Doctoral dissertation, MIT. [Published by the Indiana University Linguistics Club, Bloomington, 1976].

Nelson, Katherine (1973) Structure and Strategy in Learning to Talk, Monographs of the Society for Research in Child Development 38.

Quirk, Randolph, Sidney Greenbaum, Geoffrey Leech, and Jan Svartvik (1985) A Comprehensive Grammar of the English Language, Longman, London.

Rothstein, Susan (1983) The Syntactic Forms of Predication, Doctoral dissertation, MIT.

Safir, Kenneth (1985) Syntactic Chains, Cambridge University Press, Cambridge.

Slobin, Dan (1973) "Cognitive Prerequisites for the Development of Grammar," Studies of Child Language Development, ed. by Charles Ferguson and Dan Slobin, 175-208, Holt, Rinehart and Winston, New York.

Stowell, Tim (1978) "What Was There Before There Was There," CLS 14, $458-471$.

Stowell, Tim (1981) Origins of Phrase Structure, Doctoral dissertation, MIT.

Takahashi, Hiroshi (1990) "There-Koobun no Kai-Taipu ni tsuite (On the Subtypes of There-Constructions)," Eigo Kyoiku 39.6, 68-71; 39.8, 68-71.

Williams, Edwin (1984) “There-Insertion," Linguistic Inquiry 15, 131-153.

Zandvoort, R. W. (1962) A Handbook of English Grammar, Longman, London.

Graduate School of Human Informatics

Nagoya University

Chikusa-ku, Nagoya-shi

Aichi 464-01

e-mail: g44227a@nucc.cc.nagoya-u.ac.jp 